\title{
The 6-meter Breadboard Antenna for the Deep Space Network Large Array ${ }^{1}$
}

\author{
William A. Imbriale, Sander Weinreb, Alfonso Feria, Chris Porter, Dan Hoppe and Mike Britcliffe \\ Jet Propulsion Laboratory, California Institute of Technology \\ 4800 Oak Grove Drive \\ Pasadena, CA 91109 \\ 818-354-5172 \\ William.A.Imbriale@J.Jpl.Nasa.Gov
}

\begin{abstract}
Development of very large arrays of small antennas has been proposed as a way to increase the downlink capability of the NASA Deep Space Network (DSN) by two or three orders of magnitude thereby enabling greatly increased science data from currently configured missions or enabling new mission concepts. The current concept is for an array of $400 \times 12-\mathrm{m}$ antennas at each of three longitudes [1]. The DSN array will utilize radio astronomy sources for phase calibration and will have wide bandwidth correlation processing for this purpose. A program is currently underway to develop the technology and prove the performance and cost of a very large DSN array. The program includes a 3-element interferometer to be completed by late 2004 . This paper describes the design and development of the low cost 6-meter breadboard antenna to be used as part of the interferometer.
\end{abstract}

\section{TABLE OF CONTENTS}

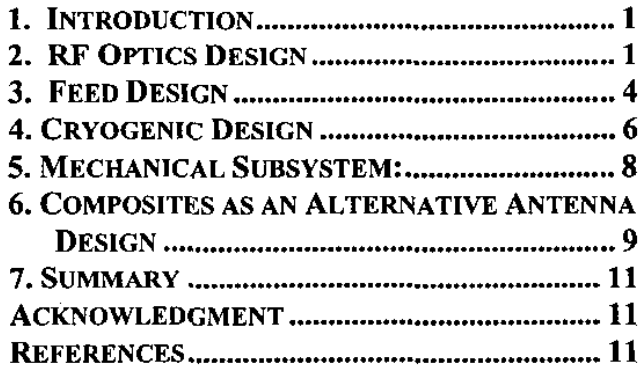

\section{INTRODUCTION}

The baseline breadboard antenna is a 6-meter hydroformed symmetrically shaped dual reflector system utilizing Gregorian optics. The heritage for this antenna lies in the Allen Telescope Array project plans to build 350 6-m antennas specified for use up to $11 \mathrm{GHz}$. Hydroforming is the process of forming aluminum to a rigid and precise mold by using a fluid or gas under pressure. It has been highly developed for use in production of low-cost reflectors for satellite communications and thousands of antennas in the 1 to 4 meter range have been manufactured. This project improves the rms of the surface to extend the useable

\footnotetext{
0-7803-8155-6/04/\$17.00 $\bigcirc 2004$ IEEE
}

frequency range to $40 \mathrm{GHz}$. The backup structure utilizes 9 equally spaced aluminum struts connecting a center yoke to the rim of the dish. The pedestal consists of a central pipe tucked under the dish with a central bearing for azimuth motion and a jackscrew for elevation control.

Also under consideration, as an alternative design for the hydroformed dishes, is an antenna manufactured from composite materials. Composite materials have proven mechanical and structural properties that are superior to metals, at a reduced weight. The major challenge with this type of structure is the cost. But new manufacturing processes and novel implementations are expected to reduce the cost of manufacturing considerably. Other challenges that need to be resolved include the environmental performance and finding a suitable material to incorporate as the reflective surface.

The feed is a dual frequency hom covering the $\mathrm{X}(8-9 \mathrm{GHz})$ and $\mathrm{Ka}(30-40 \mathrm{GHz})$ bands. The X-band will be a coaxial waveguide fed corrugated horn and $\mathrm{Ka}$-band will utilize a dielectric rod in the center of the corrugated horn.

\section{RF OptICS DESIGN}

An early design for the antenna proposed by Vahraz Jamnejad [2] was designed for optimal gain, not the desired optimal gain to noise temperature ratio. His design demonstrated a gain of $52.82 \mathrm{~dB}$ and a $\mathrm{G} / \mathrm{T}$ of $38.49 \mathrm{~dB} / \mathrm{K}$ (assuming a $240 \mathrm{~K}$ ambient temperature and an amplifier noise temperature of $15 \mathrm{~K}$ ). It was calculated that an antenna designed for optimal $\mathrm{G} / \mathrm{T}$, however, would yield a $\mathrm{G} / \mathrm{T}$ of $40.9 \mathrm{~dB} / \mathrm{K}$. Unfortunately, the main reflector profile of Jamnejad's antenna had already been submitted for fabrication. Therefore, the antenna was redesigned for the maximum G/T attainable, by reshaping the subreflector and moving the feed location, while retaining the main reflector design.

\section{Optimizing for $G / T$}

In a dual reflector antenna geometrical optics shaped for maximum gain, the main reflector is illuminated by the subreflector in such a way as to produce a uniform aperture distribution [3]. This utilizes a subreflector pattern that has a high edge taper that is truncated to zero at the edge of the 
main reflector. Unfortunately, due to diffraction effects, a real subreflector pattern does not go to zero at the main reflector edge and there is substantial spillover in the rear direction. This spillover sees the hot earth and consequently increases the noise temperature of the antenna system. The DSN has typically dealt with this problem in two ways. 1) Select the uniform illumination function of the main reflector to be less than the physical aperture, thus using the remainder of the aperture as a noise shield thus reducing the spillover energy that falls on the hot earth or 2) Select the illumination function to be uniform to a give radius and then taper it to zero at the reflector edge, also reducing the rear spillover. The 70-meter antennas, the HEF, DSS-13 and the ARST antennas used method 1) and the operational BWG antennas used method 2). Both methods yield virtually identical results for $\mathrm{G} / \mathrm{T}$.

Since the problem with the maximum gain design is the rear spillover, it is possible to reduce the rear spillover by truncating the subreflector and letting the power spill in the forward direction, which only sees the cold sky. However, the reduction in subreflector size necessary to significantly reduce the real spillover loses a significant fraction of the gain to forward spillover. The maximum $\mathrm{G} / \mathrm{T}$ obtainable using this method is about $1 \mathrm{~dB}$ below the optimum $\mathrm{G} / \mathrm{T}$.

Another method to reduce the forward spillover is to move the feed forward of the design position and then reshape the subreflector for perfect phase in the aperture. Selecting the amount of the main reflector illuminated by the subreflector controls the rear spillover. The position of the feed and the amount of the main reflector illuminated are the two parameters to be optimized. For each feed location and illumination radius, the subreflector was reshaped for uniform phase in the aperture. Figure 1 summarizes the results of the simulations.

Not included in the analysis was the feed blockage from the subreflector-scattered field. In order to ensure against undesired blockage from the horn with a displacement too extreme, a $0.2 \mathrm{~m}$ maximum displacement was chosen. The corresponding main reflector uniform illumination that yielded the greatest $\mathrm{G} / \mathrm{T}$, a $2.9 \mathrm{~m}$ illumination radius, was then chosen. This design demonstrates a gain of $53.56 \mathrm{~dB}$ and a $\mathrm{G} / \mathrm{T}$ of $40.77 \mathrm{~dB} / \mathrm{K}$ at $8.4 \mathrm{GHz}$, a $2.28 \mathrm{~dB} / \mathrm{K} \mathrm{G} / \mathrm{T}$ increase from the original design.

The above calculations were based upon a feed phase center selected for maximum gain. Optimizing the feed phase center location for maximum G/T then further increased this performance. After performing analysis to determine the optimal feed position for the antenna, we determined that a $0.00508 \mathrm{~m}$ offset yielded optimal performance over the bandwidth. This further increased the $\mathrm{G} / \mathrm{T}$ to $40.82 \mathrm{~dB} / \mathrm{K}$, with an associated gain of $53.50 \mathrm{~dB}$. This final design yields a $2.33 \mathrm{~dB} / \mathrm{K}$ increase of $\mathrm{G} / \mathrm{T}$ from the original design.

Figure 2 demonstrates the performance of the final antenna; which has $0.2 \mathrm{~m}$ feed displacement for the original design, a
$2.9 \mathrm{~m}$ uniform illumination radius, and $0.00508 \mathrm{~m}$ feed phase center offset. The chart has the data with the calculated radiation patterns of the feed as well as some measured feed patterns in the $89 \mathrm{GHz}$ and $3040 \mathrm{GHz}$ bandwidths.

\section{G/T Estimates}

The above calculations were done primarily for tradeoff comparisons and did not include all the estimated losses that would be common to all designs. The above results included the calculated losses from the PO programs and an estimated $15 \mathrm{~K}$ noise temperature contribution from the low noise amplifier system at X-band and $40 \mathrm{~K}$ at $\mathrm{Ka}$-band. The purpose of this section is to provide a more complete G/T performance estimate including the expected uncertainties.

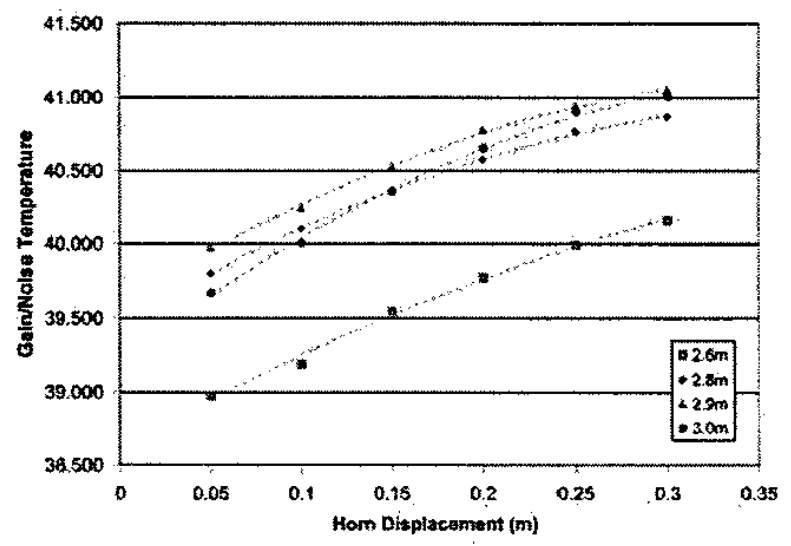

Figure 1 - G/T vs. Horn Displacement for Various Illumination Radius

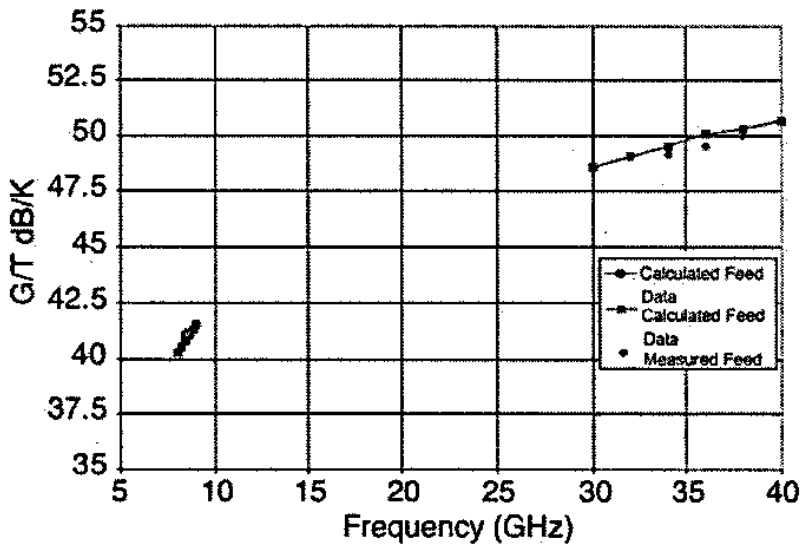

Figure 2 - G/T Performance Across Bandwidth

Tables 1 and 2 give the performance estimates for the Xand $\mathrm{Ka}$-band low noise amplifiers. These are the wideband MMIC design. A typical estimate for the system noise temperature is shown in Table 3 and a typical gain budget shown in Table 4. Utilizing the data from these tables along with the PO calculated gain as a function of frequency utilizing the theoretical feed patterns, the maximum and minimum estimate G/T is shown in Figure 3. Further details on sensitivity performance can be found in Reference [4]. 
Table 1. X-band Noise Budget (S. Petty/M. Britcliffe)

\begin{tabular}{|c|c|c|c|c|c|c|c|c|c|c|}
\hline \multirow[b]{2}{*}{ Item } & \multicolumn{2}{|c|}{ Loss $L(d B)$} & \multicolumn{2}{|c|}{ Phy Temp T, K } & \multicolumn{2}{|c|}{ Gain $\mathrm{G}, \mathrm{dB}$} & \multicolumn{2}{|c|}{ Tin, $\mathrm{K}$} & \multicolumn{2}{|c|}{ Noise, $\mathrm{K}$} \\
\hline & Goal & $\operatorname{Max}$ & Goal & $\operatorname{Max}$ & Goal & $\operatorname{Max}$ & Goal & $\operatorname{Max}$ & Goal & $\operatorname{Max}$ \\
\hline \multicolumn{9}{|c|}{ Mismatch loss, vacuum window (included in vacuum window resistive loss term below) } & 0.00 & 0.00 \\
\hline \multicolumn{9}{|c|}{$\mathrm{X}$-band combiners isolation noise term. Isolation $=26 \mathrm{~dB}$ goal, $23 \mathrm{~dB}$ max } & 0.03 & 0.06 \\
\hline \multicolumn{9}{|c|}{$\mathrm{X}$-band polarizer isolation noise term. Isolation $=23 \mathrm{~dB}$ goal, $20 \mathrm{~dB}$ max } & 0.06 & 0.12 \\
\hline Vacuum window & 0.004 & 0.015 & 293 & 293 & & & & & 0.29 & 1.00 \\
\hline \multicolumn{11}{|c|}{$\begin{array}{l}\text { Goal: } 11 \text { mil Teflon, } 3 \text { mil Kapton, } 1 \text { " Propozote } \\
\text { Max: } 11 \text { mil Teflon, } 0.25 \text { " Rexolite, 1" Propozote }\end{array}$} \\
\hline Feedhorn & 0.008 & 0.014 & 50 & 60 & & & & & 0.10 & 0.19 \\
\hline Teflon torpedo/foam support & 0.015 & 0.020 & 20 & 30 & & & & & 0.07 & 0.14 \\
\hline Waveguide $\mathrm{Cu} 1.5$ inches & 0.002 & 0.003 & 15.0 & 16.0 & & & & & 0.08 & 0.19 \\
\hline Slot combiner & 0.025 & 0.050 & 13.0 & 15.0 & & & & & 0.08 & 0.18 \\
\hline $\begin{array}{l}\text { WR } 1127.5 \text { inches straight, } 2 \text { miter } \\
\text { bends }\end{array}$ & 0.027 & 0.050 & 13.0 & 15.0 & & & & & 0.08 & 0.18 \\
\hline Slot combiner & 0.025 & 0.050 & 13.0 & 15.0 & & & & & 0.08 & 0.18 \\
\hline Hybrid polarizer & 0.030 & 0.050 & 13.0 & 15.0 & & & & & 0.09 & 0.18 \\
\hline WR bend & 0.006 & 0.008 & 13.0 & 14.0 & & & & & 0.02 & 0.03 \\
\hline WR cal coupler (loss) & 0.025 & 0.035 & 13.0 & 14.0 & & & & & 0.08 & 0.12 \\
\hline WR cal coupler (inj noise) & 30.0 & 29.0 & 293 & 293 & & & & & 0.30 & 0.39 \\
\hline \multicolumn{11}{|c|}{$\begin{array}{l}\text { Goal: Coupler integrated in MMIC module } \\
\text { Max: Coupler separate (same performance) }\end{array}$} \\
\hline WR/SMA male adapter & 0.090 & 0.120 & 13.0 & 6.9 & & & & & 0.28 & 0.21 \\
\hline MMIC HEMT module & & & & & 35.0 & 31.0 & 4.00 & 7.00 & 4.24 & 7.70 \\
\hline 0.141 output coax, $12-70 \mathrm{~K}$ & 0.56 & 0.67 & 50 & 50 & & & & & 0.00 & 0.01 \\
\hline 0.141 output coax, $70-293 \mathrm{~K}$ & 0.56 & 0.67 & 210 & 210 & & & & & 0.01 & 0.04 \\
\hline Loss between vacuum feed & 0.40 & 0.50 & 293 & 293 & & & & & 0.01 & 0.04 \\
\hline $\begin{array}{l}\text { through, receiver assembly } \\
\text { Receiver assembly }\end{array}$ & & & & & & & 150 & 250 & 0.15 & 0.90 \\
\hline \multicolumn{9}{|c|}{ Input Noise Temp Te(K) } & 6.14 & 12.35 \\
\hline
\end{tabular}

Table 2. Ka-band Noise Budget (S. Petty/M. Britcliffe)

\begin{tabular}{|c|c|c|c|c|c|c|c|c|c|c|}
\hline \multirow[b]{2}{*}{ Item } & \multicolumn{2}{|c|}{ Loss L (dB) } & \multicolumn{2}{|c|}{ Phy Temp T, K } & \multicolumn{2}{|c|}{ Gain $\mathrm{G}, \mathrm{dB}$} & \multicolumn{2}{|c|}{ Tin, $\mathrm{K}$} & \multicolumn{2}{|c|}{ Noise, $\mathrm{K}$} \\
\hline & Goal & Max & Goal & $\operatorname{Max}$ & Goal & $\operatorname{Max}$ & Goal & $\operatorname{Max}$ & Goal & $\operatorname{Max}$ \\
\hline \multicolumn{9}{|c|}{ Mismatch loss, vacuum window (included in vacuum window resistive loss term below) } & $\begin{array}{l}0.00 \\
0.25 \\
\end{array}$ & $\begin{array}{l}0.00 \\
0.35 \\
\end{array}$ \\
\hline Vacuum window & 0.015 & 0.038 & 293 & 293 & & & & & 1.01 & 2.57 \\
\hline \multicolumn{11}{|c|}{$\begin{array}{l}\text { Goal: } 11 \text { mil Teflon, } 3 \text { mil Kapton, } 1 \text { "Propozote } \\
\text { Max: } 11 \text { mil Teflon, } 0.25 \text { " Rexolite, } 1 \text { "Polystyrene }\end{array}$} \\
\hline $\begin{array}{l}\text { Feedhom } \\
\text { Teflon torpedo/foam support } \\
\text { Round WG Cu } 4.0 \text { inches } \\
\text { Hybrid polarizer } \\
\text { WR28 waveguide bend } \\
\text { WR28 } 30 \mathrm{~dB} \text { cal coupler (loss) } \\
\text { WR28 } 30 \mathrm{~dB} \text { cal coupler (inj noise) }\end{array}$ & $\begin{array}{l}0.020 \\
0.045 \\
0.004 \\
0.050 \\
0.005 \\
0.060 \\
30.0 \\
\end{array}$ & $\begin{array}{l}0.032 \\
0.060 \\
0.006 \\
0.075 \\
0.005 \\
0.060 \\
29.0 \\
\end{array}$ & $\begin{array}{l}50 \\
20 \\
15.0 \\
13.0 \\
13.0 \\
13.0 \\
293 \\
\end{array}$ & $\begin{array}{l}60 \\
30 \\
18.0 \\
15.0 \\
15.0 \\
15.0 \\
293\end{array}$ & & & & & $\begin{array}{l}0.23 \\
0.21 \\
0.01 \\
0.15 \\
0.02 \\
0.19 \\
0.31\end{array}$ & $\begin{array}{l}0.45 \\
0.42 \\
0.03 \\
0.27 \\
0.02 \\
0.22 \\
0.39\end{array}$ \\
\hline \multicolumn{11}{|c|}{$\begin{array}{l}\text { Goal: Coupler integrated in MMIC module } \\
\text { Max: Coupler separate }\end{array}$} \\
\hline $\begin{array}{l}\text { MMIC HEMT module } \\
\text { Output coax, 12-70K, } 8 \text { in. long } \\
\text { Output coax, } 70-293 \mathrm{~K}, 8 \text { in. long } \\
\text { Loss between vacuum feed through, } \\
\text { receiver assembly } \\
\text { Receiver assembly }\end{array}$ & $\begin{array}{l}2.00 \\
2.00 \\
1.00\end{array}$ & $\begin{array}{l}2.50 \\
2.50 \\
1.40\end{array}$ & $\begin{array}{r}50 \\
210 \\
293\end{array}$ & $\begin{array}{c}50 \\
210 \\
293\end{array}$ & 40.0 & 38.0 & 600 & 800 & $\begin{array}{r}15.70 \\
0.00 \\
0.02 \\
0.02 \\
\\
0.42 \\
\end{array}$ & $\begin{array}{r}23.44 \\
0.01 \\
0.05 \\
0.06 \\
\\
1.59 \\
\end{array}$ \\
\hline \multicolumn{9}{|c|}{ Input Noise Temp Te(K) } & 18.6 & 30.2 \\
\hline
\end{tabular}


Table 3. Typical Noise Temperature Budget

\begin{tabular}{|l|c|c|l|}
\hline \multirow{2}{*}{\multicolumn{1}{|c|}{ Element }} & \multicolumn{2}{|c|}{ Noise, K } & \multirow{2}{*}{ Note } \\
\cline { 2 - 4 } & X-band, 8.4 GHz & K-band, 32 GHz & \multicolumn{1}{|c}{ Effective blackbody } \\
Cosmic background & 2.5 & 2.0 & Goldstone (ave clear) \\
Atmosphere & 2.2 & 7.0 & $6 \%$ at X-band \\
Forward spill & 0.3 & 0 & \\
Main reflector rear spill & 3.6 & 1.0 & Aluminum \\
Main reflector I ${ }^{2} \mathrm{R}$ & 0.1 & 0.2 & Aluminum \\
Subreflector I ${ }^{2} \mathrm{R}$ & 0.1 & 0.2 & Estimated \\
Quadripod scatter & $2 / 4$ & $2 / 4$ & Tables 1 and 2 \\
Feed/amplifier cont & $6.1 / 12.4$ & $18.6 / 30.2$ & \\
\hline Total Noise, $\mathrm{K}$ & $16.9 / 25.2$ & $31.0 / 44.6$ & \\
\hline
\end{tabular}

Table 4. Typical Efficiency Budget

\begin{tabular}{|c|c|c|c|}
\hline \multirow[b]{2}{*}{ Element } & \multicolumn{2}{|c|}{ Efficiency } & \multirow[b]{2}{*}{ Note } \\
\hline & $\mathrm{X}$-band, $8.4 \mathrm{GHz}$ & $\mathrm{K}$-band, $32 \mathrm{GHz}$ & \\
\hline P.O. computed & 0.777 & 0.780 & $\begin{array}{l}100 \%=54.59-\mathrm{X} \\
100 \%=66.21-\mathrm{Ka}\end{array}$ \\
\hline Main Reflector & & & \\
\hline$I^{2} R$ & 0.999 & $\begin{array}{l}0.999 \\
0.846\end{array}$ & \\
\hline RMS & 0.988 & 0.846 & 12 mils RMS \\
\hline Subreflector & & & \\
\hline $\begin{array}{l}\mathrm{I}^{2} \mathrm{R} \\
\mathrm{RMS}\end{array}$ & $\begin{array}{l}0.999 \\
0.999\end{array}$ & $\begin{array}{c}0.999 \\
0.8982\end{array}$ & 4 mils RMS \\
\hline Feed support blockage & $0.85 / 0.9$ & $0.85 / 0.9$ & Estimated \\
\hline Feed VSWR & 0.999 & 0.999 & \\
\hline $\begin{array}{l}\text { Efficiency } \\
\text { Gain (dB) }\end{array}$ & $\begin{array}{l}0.650 / 0.688 \\
52.72 / 52.97\end{array}$ & $\begin{array}{l}0.549 / 0.581 \\
63.61 / 63.85\end{array}$ & \\
\hline
\end{tabular}

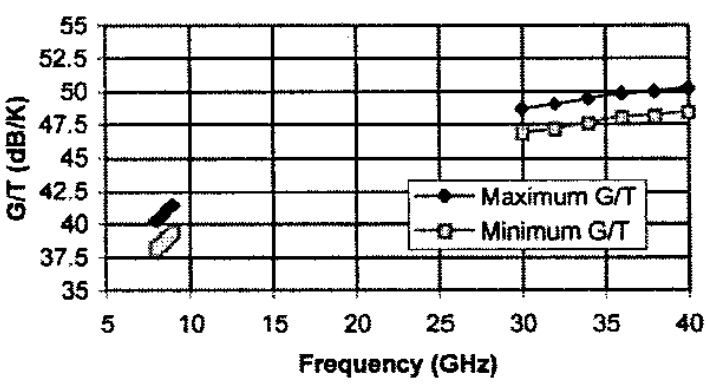

Figure 3 - Maximum and Minimum G/T

\section{Feed Design}

The basic requirements for the feed are to optimally cover the DSN X- (8.4-8.5 GHz) and $\mathrm{Ka}-(31.8-32.2 \mathrm{GHz})$ frequency receive bands and provide useable performance over the $8-9 \mathrm{GHz}$ and $30-40 \mathrm{GHz}$ frequency bands. The polarization is dual circular at both bands with ellipticity
$<0.75 \mathrm{~dB}$ over the DSN bands. The retum loss is to be better than $20 \mathrm{~dB}$ over the useable bands. The target illumination function of $-12 \mathrm{~dB}$ at 42 degrees off main beam direction was selected to be the same as the ATA feed so there was the possibility of using the ATA offset reflectors. Considerations for low cost mass production were also to be included in the design.

After exploring several options, the selected design was an $\mathrm{X} / \mathrm{Ka}$ band coaxial feed that includes a dielectric rod for Kaband radiation as shown on Figure 4 . The radiation pattern at X-band was controlled by slot depth and flare angle to produce saturated operation and the radiation pattern at Kaband controlled by the dielectric rod profile. X-band enters the horn throat via a TE11 coax mode and Ka-band enters conventionally. Both bands use a commercial fin type polarizer. A picture of a linear polarization prototype feed is shown in Figure 5. More details of the feed design and performance can be found in Reference [5]. 


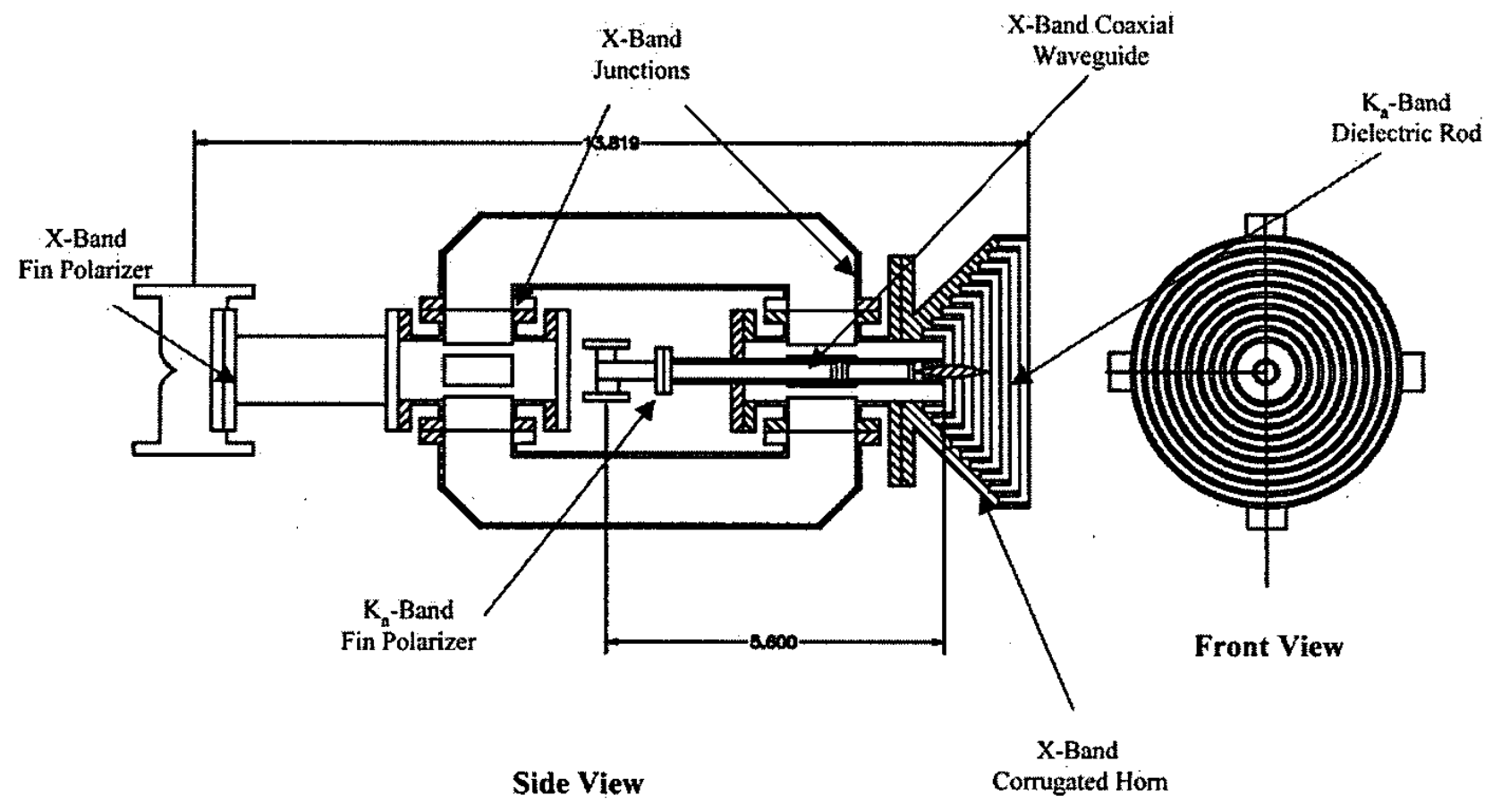

Figure 4 - The X/Ka Band Coaxial Feed

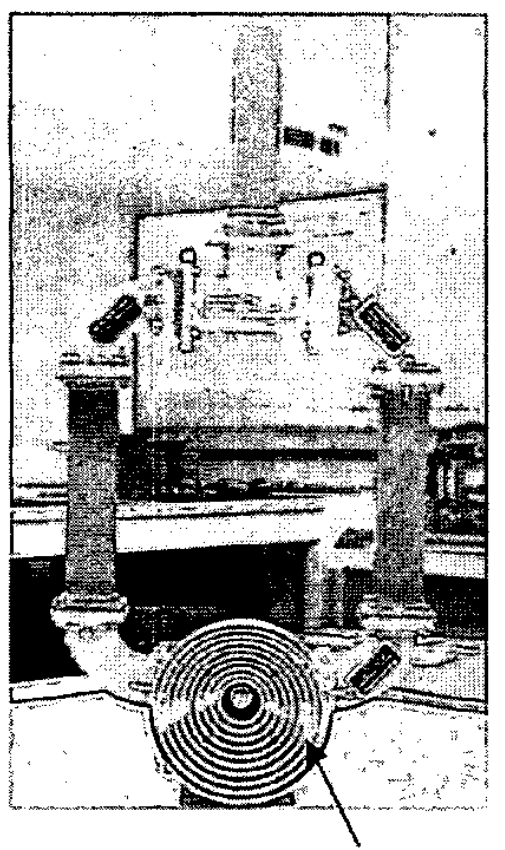

Corrugated Horn

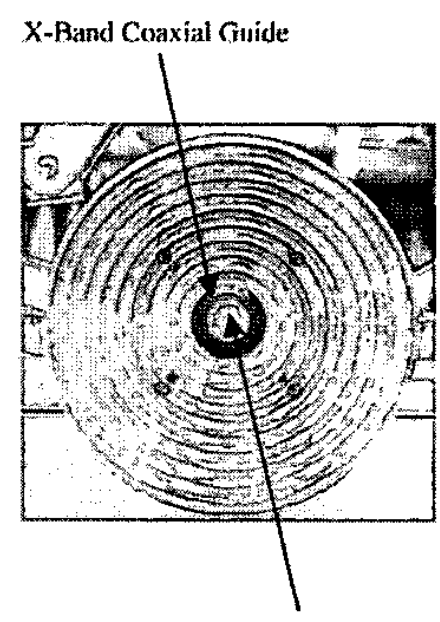

Ka-Band

Dielectric Rod

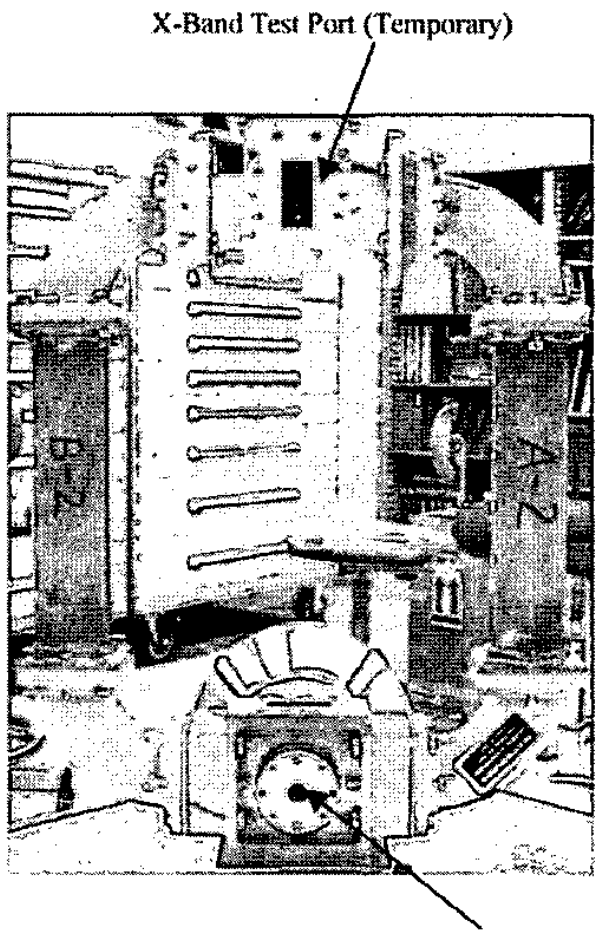

Ka-Band Port

Figure 5 - Prototype Feed - Linear Polarization Test Model 


\section{Cryogenic Design}

The following describes the design and performance of a prototype LNA system for The Deep Space Network (DSN) Large Array Task. The system cools a dual frequency feed system equipped with HEMT low noise amplifiers and the associated support electronics. The system was designed to be manufactured at minimum cost. The design considerations including the cryocooler, the vacuum system, microwave interconnects, mechanical components and radiation shielding are discussed. Further details can be found in reference [6].

\section{Cryocooler Selection}

One challenge in the design of the large array LNA system is minimizing the cost of electrical power. Estimates of the operations cost of an array with 100's to 1000's of array elements show that power costs for LNA cooling are the biggest single operating cost of the LNA system. Two refrigerators showed promise. Both were Gifford-McMahon two stage coolers with first stage operating temperatures near $50 \mathrm{~K}$ and second stage temperatures near $15 \mathrm{~K}$.

The CTI Cryogenics model 350 are systems that produced 3 watts of cooling at $15 \mathrm{~K}$. The input power requirement is $1.8 \mathrm{~kW}$. The design has been used in hundreds of LNA systems over a 40 -year span. The units typically operate for 18000 hours before requiring maintenance.

The second was Cryomech Inc. model GB-15 systems. The GB-15 is similar to the original Gifford-McMahon cooler evaluated by JPL in the 1960's. These are GiffordMcMahon (GM) systems that produce 1.5 watts of cooling at $15 \mathrm{~K}$. The power consumption is $1.2 \mathrm{~kW}$.

\section{Cryogenic Heat Load}

The heat load on the cryocooler is the sum of load imposed by the LNA and supporting components from any residual gas in the vacuum space. Conduction load is through solid supports, wires, signal cables and the residual gas in the vacuum space. Radiation is from the room temperature surroundings to the cryogenic components.

The first stage of the cooler intercepts the radiation load from room temperature to the cooled components with the radiation shield. The first stage is also used to minimize heat conducted to the second stage by thermally connecting solids connected between room temperature and the second stage.

This system includes a cryogenically cooled feed and feed horn. The horn has a $12 \mathrm{~cm}$ aperture that is subject to radiation from ambient. The $12 \mathrm{~cm}$ feed is the largest cooled aperture that has been used in the DSN in a closed-cycle cooling system.

The system imposes a heat load of 10 watts on the first stage and 1 watt on the second stage of the cooler. Radiation loading from the cooled feed accounts for over 50 percent of the $2^{\text {nd }}$ stage heat load.

\section{Mechanical Layout}

To evaluate both coolers the prototype cooler was designed to accept both the CTI 350 and the Cryomech GB-15. The package is housed in $25 \mathrm{~cm}$ diameter $42 \mathrm{~cm}$ long round vacuum housing. The feed and cooler are offset to provide the most usable space in the cold volume. The assembly is designed to use the Cryomech GB-15 and CTI model 350 coolers interchangeably with only bolt-in modification.

The vacuum housing chosen for the breadboard system is constructed using aluminum tubing. It eliminates welding and the problems associated with vacuum leaks and warping. In production runs this technique can be cost effective. It provides the benefit of minimum weight and allows the vacuum housing to be sized optimally.

The end plate for the vacuum housing uses the standard machined aluminum plate design. The plate is fitted with simple gland-seal $\mathrm{O}$-ring connections. It uses commercial coax interface connectors. The feed is supported mechanically from the base plate with G-10 fiberglass supports. The feed installed is shown in Figure 6. There is no mechanical connection from the opposite end plate. This design has several advantages: It provides minimal heat conduction to cooled components. It allows the package to be easily assembled and minimizes mechanical stress due to thermal expansion.

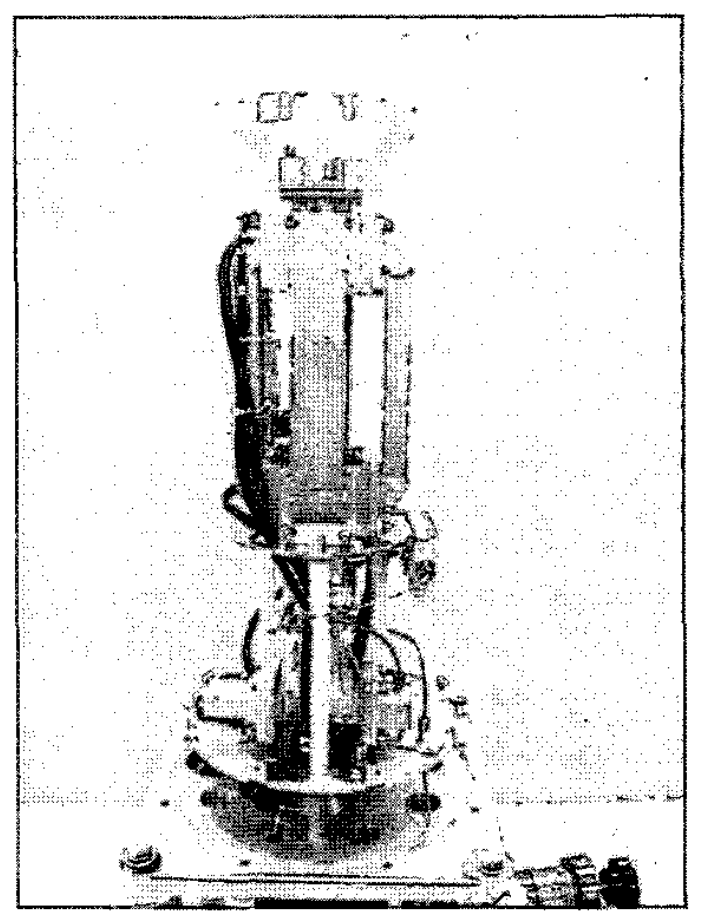

Figure 6 - Feed Installed in LNA Assembly 
In an effort to reduce manufacturing costs the mechanical hardware was constructed using sheet metal technology wherever possible. The radiation shield is a simple rolled cone. It is attached with screws to the flanges that are also simple sheet metal parts. It eliminates costly and time consuming welding or silver brazing used in traditional DSN designs. Normally copper is used for shields. The radiation shields for the prototype are constructed of $1100 \mathrm{~F}$ alloy aluminum. The aluminum provides acceptable thermal conductivity for the application and provides higher resistance to oxidation and is lighter than copper. The Radiation shield installed on the cooler is shown in Figure 7.

\section{Feed Window Design}

The vacuum window is a critical component in the package design. A foam backed membrane window was chosen for the prototype design. In this approach the film strength of a material such as Kapton provides the vacuum seal and the mechanical strength. Low-loss low-density foam acts as a thermal insulator and provides additional compressive strength.

To determine the required Kapton thickness Burst tests were performed on a typical clamped ring joint. The expected burst pressure for a $14 \mathrm{~cm}$ Kapton window was extrapolated from burst measurements of $2.2 \mathrm{~cm}$ and $9 \mathrm{~cm}$. To provide a burst pressure safety factor of 3 the window would require 0.08 to $0.13 \mathrm{~mm}$ Kapton film.

Kapton windows lose mechanical strength when exposed to the sun. To solve this problem a thin Teflon cloth is used as an outer layer over the Kapton. Gore manufactures a reduced density Teflon cloth with an advertised 30-year life in radome service.

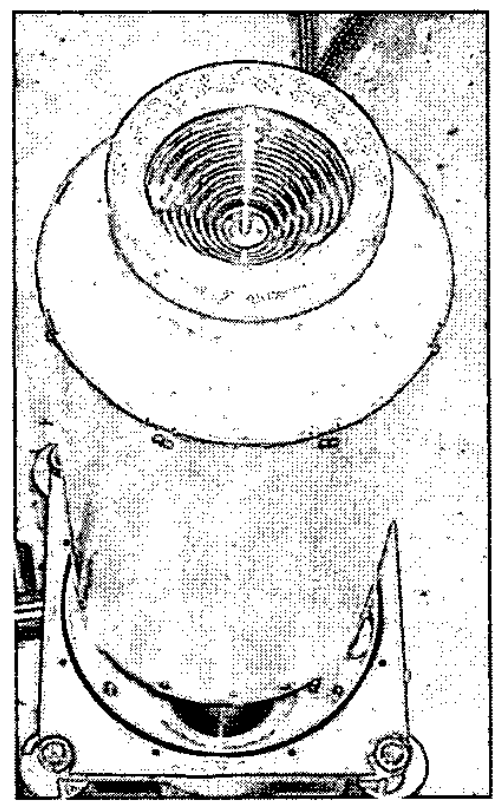

Figure 7 - Radiation Shield Installed
The prototype window is constructed of $0.08 \mathrm{~mm}$ Kapton covered with $0.38 \mathrm{~mm}$ Teflon cloth and is backed by $25 \mathrm{~mm}$ of polystyrene foam. The resulting noise temperature of the window is less than $1 \mathrm{~K}$. Figure 8 shows the cooler/LNA with the window installed.

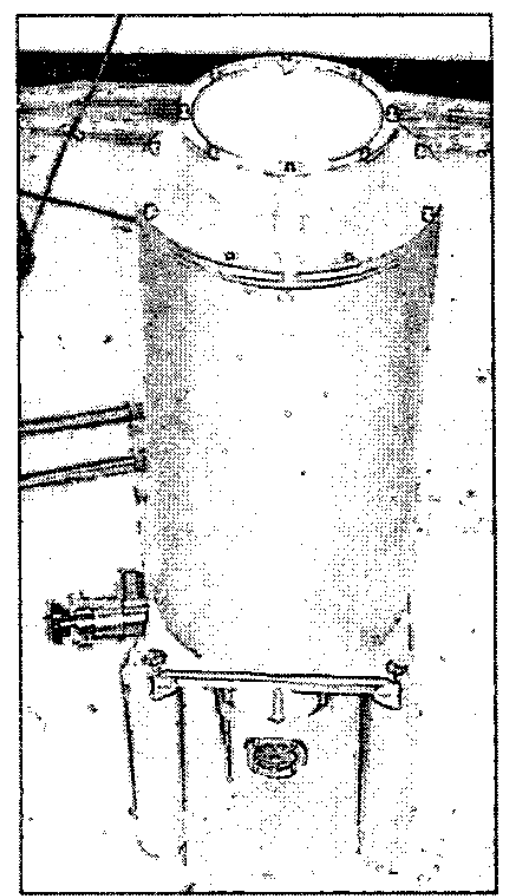

Figure 8 - Vacuum Window Installed on LNA Assembly

\section{Vacuum System}

The vacuum system is a critical component of the array LNA. A vacuum pressure of $<10^{-5}$ Torr is required in the vacuum space to minimize the heat leak to the cooled components. The array LNA uses a "cryopump" to maintain the vacuum pressure. A schematic of the vacuum system is shown in Figure 9.

Choice of Materials for Cooled Microwave HardwareCopper is normally used for most DSN microwave components. It provides the highest thermal conductivity (5w/cm-K@15K) of any practical material. It also has the lowest surface resistivity that affects the noise temperature contribution of microwave components. The noise temperature contribution to an LNA system associated with input waveguide loss is affected by two factors:

1) To the first-order the noise contribution of any given conductor is proportional to the absolute temperature from the equation: Tnoise $=$ Tphysical (1-loss).

2) The loss is also proportional to the square root of the material surface resistivity that decreases with temperature. 


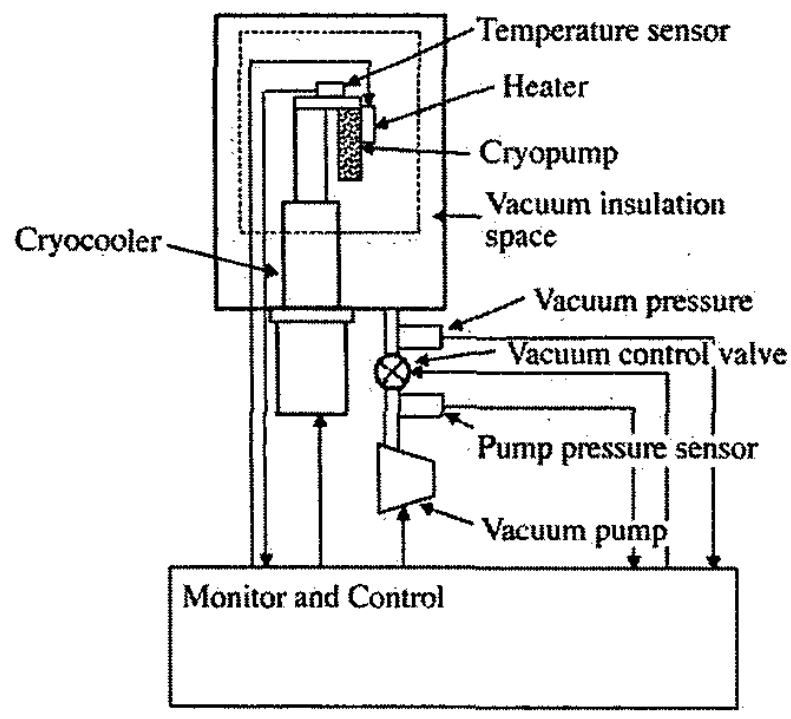

Figure 9 - Vacuum and Cryogenic System Schematic

The DSN typically specifies copper for waveguide in LNA systems. In the large array systems there may be an advantage in using aluminum waveguide to reduce manufacturing cost and the mass of feed components. The waveguide size is WR-112 for $8.4 \mathrm{GHz}$ and WR-28 for $32 \mathrm{GHz}$. At the expected operating temperature of $20 \mathrm{~K}$ or less the difference in loss of copper and aluminum waveguide is insignificant. Aluminum waveguide can therefore be used as desired.

\section{Mechanical Subsystem:}

The critical technology in the mechanical system for the reflector is the dish manufactured from a process called hydroforming. This is the process of forming aluminum to a rigid and precise mold by using a fluid or gas under pressure. It has been highly developed for use in production of low-cost reflectors for satellite communications and thousands of antennas in the 1 to 4 meter range have been manufactured. The advantages are: 1) High rigidity due to the one-piece aluminum shell (consider the stiffness of thin metal bowls or woks compared to the stiffness of flat sheets) 2) Accuracy largely determined by the mold rather than human error. The repeatability of the process was verified by fabricating 3 dishes with an $\mathrm{ms}$ of less than $0.2 \mathrm{~mm}$ and 3) Low costs for both raw material and labor.

For the DSN breadboard, the dish aperture is $6.048 \mathrm{~m}$ or $20 \mathrm{ft}$ (see Figure 10). The dish is connected to a rigid Truss Structure at two places. The dish is hard mounted to the Truss Structure at its center. Spars connect the rim of the Dish to the rear of the Truss Structure. The Truss Structure is connected to the Petal Yoke at the elevation pivot point. There is a linear actuator or Jackscrew mechanism attached to the rear of the Yoke. As the Jackscrew extends or contracts the elevation of the Main Dish is changed. The Yoke is connected to the Petal Base through a Slew Bearing, with gears on the outer ring. Two opposing motors, mounted inside the Yoke, drive the Azimuth Axis. The Dish, Truss Structure and Spars are made of aluminum. The Yoke and Pedestal Base are made of steel. The total weight of the antenna is approximately $8500 \mathrm{lbs}$. See Figure 11 for a drawing of the complete antenna.

\section{Performance Requirements}

Surface accuracy of the dish after manufacturing must be less than $0.2 \mathrm{~mm}$ rms. For either gravity, wind or temperature the change in rms cannot be greater than $0.13 \mathrm{~mm}$. The antenna is required to operate year round at temperatures from -10 to $55 \mathrm{C}$. The pointing accuracy must be less than 0.01 degrees. The rigid body displacement of the Main Dish between Antennas must be less than $0.5 \mathrm{~mm}$. Displacement of the Subreflector relative to the Main Dish must be less than $0.5 \mathrm{~mm}$. Displacement of the Feed relative to the Main Dish must be less than $1 \mathrm{~mm}$ axial and $0.5 \mathrm{~mm}$ radial. The antenna must have a range of 10 to 90 degrees in elevation and 0 to 450 degrees in Azimuth. The antenna is designed to operate up to $30 \mathrm{mph}$ winds, can drive to stow in a $50 \mathrm{mph}$ wind and survive a $100 \mathrm{mph}$ wind.

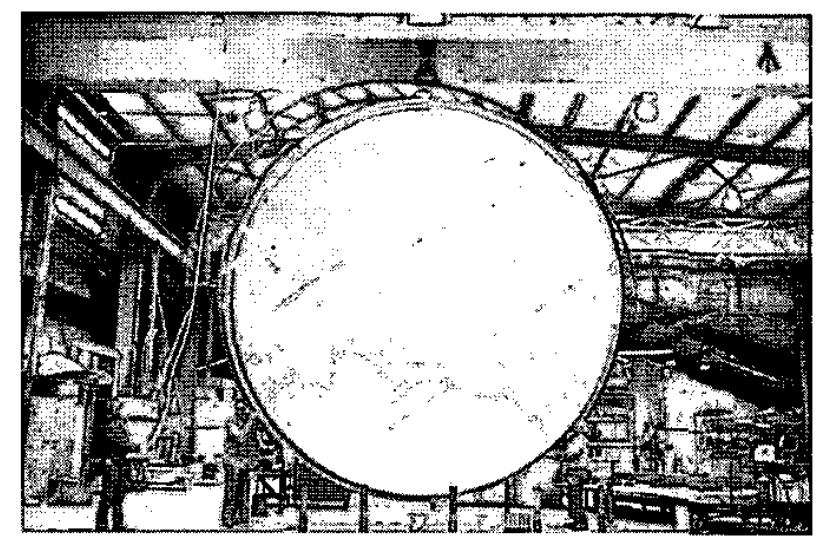

Figure 10 - Hydroformed Dish

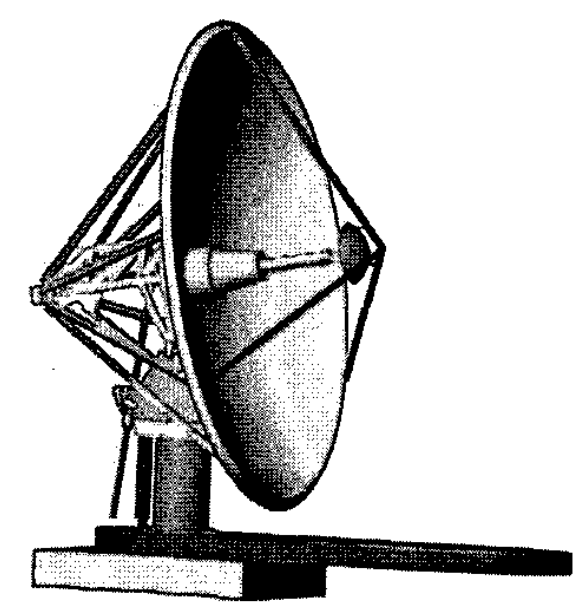

Figure 11 - The 6-meter Breadboard Antenna 


\section{Truss Structure \& Spars}

The Truss Structure is the main load-bearing substructure for the Antenna. It shares an interface with the Dish, Feed, Spars and Pedestal. The Elevation axis is located at the lower part of the Truss Structure. The loads from the jackscrew are reacted through the truss structure. The Spars, Truss Structure and Main Dish are a structural system. They work together to give the system rigidity. The Spars minimize deflection at the outer rim of the dish by transferring loads to the rear of the Truss Structure:

\section{Feed Tower}

The Feed Tower has two main structures. The cylindrical section houses the feed horn and waveguide. The conical section houses some of the electronics. The conical section is removable to allow access to service the Feed without disconnecting it from the Antenna. The cantilever loads from the feed are reacted into the Truss Structure. The Feed can be removed from the antenna without disconnecting the Dish from the Truss Structure.

\section{Pedestal}

The Pedestal consists of a Yoke and Base. The Base is stationary while the Yoke rotates about the long axis of the Base. There is a large bearing with gears that connect the Yoke to the Base. Motors mounted inside the Yoke drive the azimuth axis. There are pivots at the top of the Yoke about which the Dish and Spar rotate in the elevation axis.

\section{Cable Management System}

The azimuth axis range of motion requirement is 450 degrees. The Cable Management System forces the cable bundle to expand and contract in a planar spiral pattern. A rigid tube is connected to the Yoke. This Tube extends from the Yoke down to the bottom of the pedestal. The bottom of the tube is flared to act as a stress relief for the cable. The cable bundle is routed through this tube.

\section{Analysis}

Finite Element Analysis (FEA) was used to predict the performance of the antenna with gravity, wind and thermal loads. For any given load case the deformations of the Dish's reflective surface is extracted. Path length $\mathrm{rms}$ of these deflections is then determined. These predictions include the entire azimuth and elevation range. In addition, the frequencies of various bending modes were calculated. The FEA model is shown in Figure 12 and some typical results in Table 5. Figure 13 shows the two lowest order resonance modes.

\section{Servo Motors and Actuators}

Both the Azimuth and Elevation axis have the same Motors. The Motors are DC Servo with $110 \mathrm{~V}$ AC input. The maximum horsepower is $2.0 \mathrm{hp}$. The stall torque is 165 in*lbs. These motors can run continuously at $50 \mathrm{in}^{*} \mathrm{lbs}$ and $2000 \mathrm{mpm}$. The motors have 3000 counts per rev encoders built in. Also, each
Motor has a 240 in*lb brake. There are external encoders attached at each axis. These encoders have 144000 counts/rev and can resolve 9 arc seconds or .0025 degrees. On the azimuth axis there are two motors that work together to eliminate backlash. The motors maintain a constant counter torque. These two motors are connected to an 87:1 reducer. A pinion is connected to the output of the reducer. The motor reducer pinion combination drives a large Slew Bearing.

A linear actuator or Jackscrew is attached the rear of the yoke on a pivoting gimbal. The Jackscrews have a 20 -ton capacity and require 48 revs at the input for 1.0 inch of raise. The previously described motor drives a geared belt and pulley system which in-turn drives the Jackscrew. The ratio of the geared belt and pulley system is $1.895: 1$. To reduce Jackscrew backlash, a 2000 lb ballast mass is attached to the rear of the Truss Structure. This ballast mass keeps the linear actuator in compression for all gravity and wind load cases. The Azimuth axis drive train and elevation axis jackscrew are shown in Figure 14.

\section{Composites as an Alternative Antenna DESIGN}

With the increased popularity of composite materials, newer technologies and lower materials costs, composite materials are now an affordable, viable alternative for structural fabrication of small-to-medium size antennas.

Antennas can be fabricated with integrated backup structures to provide the stiffness required for high accuracy dish surfaces and reducing the fabrication process.

Since the thermal coefficient of expansion of carbon fiber composite materials is almost negligible, another great advantage for using this material is the significant reduction of thermal effects to avoid undesirable distortions of the reflective surface.

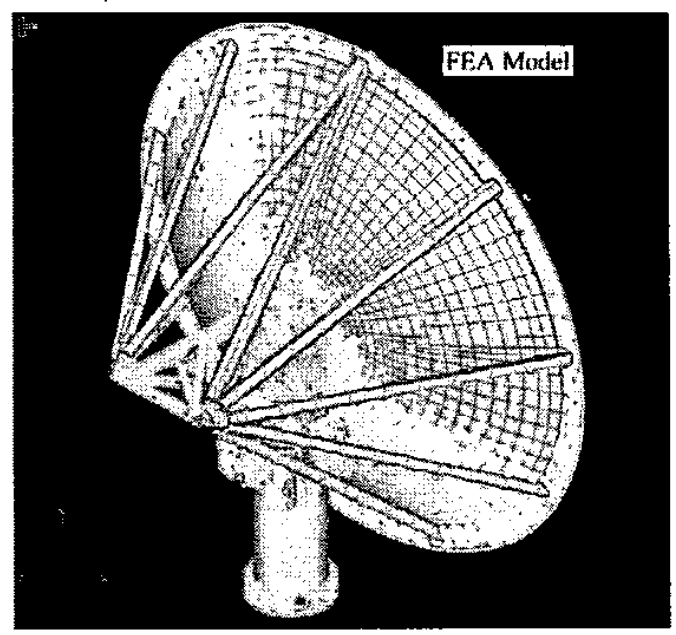

Figure 12 - The FEA Model 
Table 5. Typical Results from the FEA Model

\begin{tabular}{|c|c|c|c|c|c|}
\hline \multicolumn{6}{|c|}{ Gravity Load Elevation $=0 \mathrm{deg}$ Azimuth $=0 \mathrm{deg}$} \\
\hline $\mathrm{x}$-Tilt, deg & $\mathrm{y}$-Tilt, deg & $\begin{array}{l}\text { Surface rms } \\
\text { Including focus } \\
\text { Error, mm }\end{array}$ & $\begin{array}{c}\mathrm{x} \text {-Translation, } \\
\mathrm{mm}\end{array}$ & $\begin{array}{c}\mathrm{y} \text {-Translation, } \\
\mathrm{mm}\end{array}$ & $\begin{array}{c}\mathrm{z} \text {-Translation, } \\
\mathrm{mm}\end{array}$ \\
\hline-0.03 & 0 & 0.019 & 0 & 0 & -0.55 \\
\hline \multicolumn{6}{|c|}{ Gravity Load Elevation $=60 \mathrm{deg}$ Azimuth $=0 \mathrm{deg}$} \\
\hline-0.04 & 0 & 0.024 & 0 & 0.74 & -0.86 \\
\hline
\end{tabular}

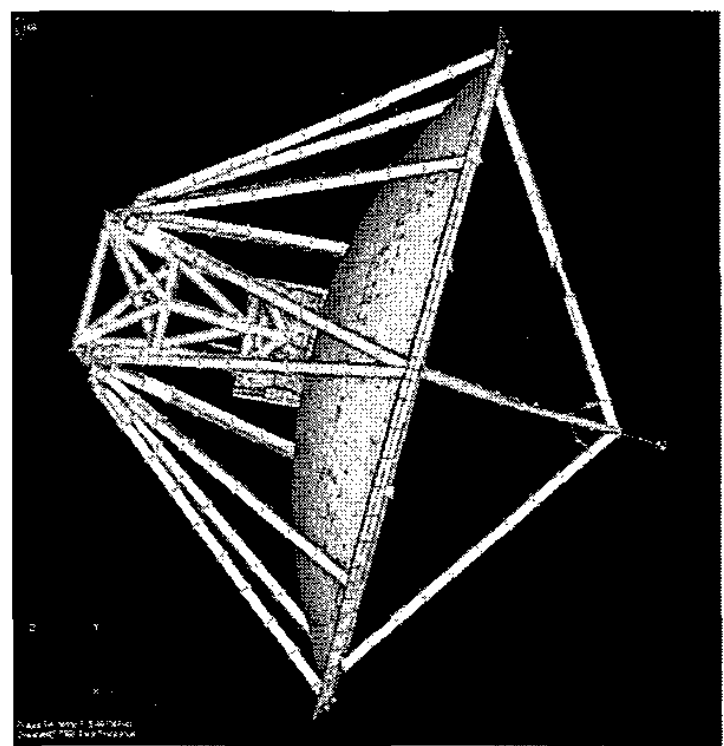

Mode 1. $5.46 \mathrm{~Hz}$ (rotation about azimuth axis)

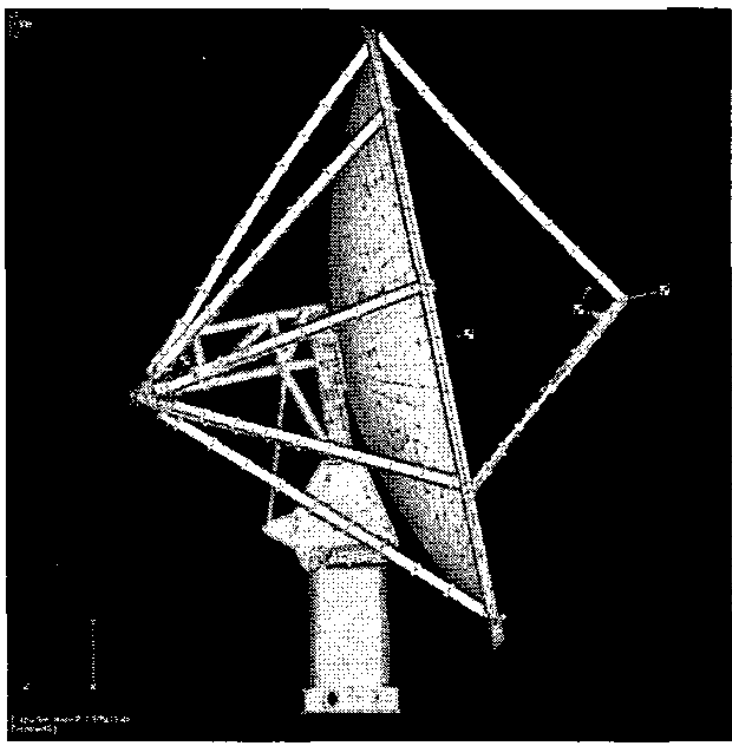

Mode 2. $7.08 \mathrm{~Hz}$ (rocking for-and-aft)

Figure 13 - The Lowest Order Resonance Modes

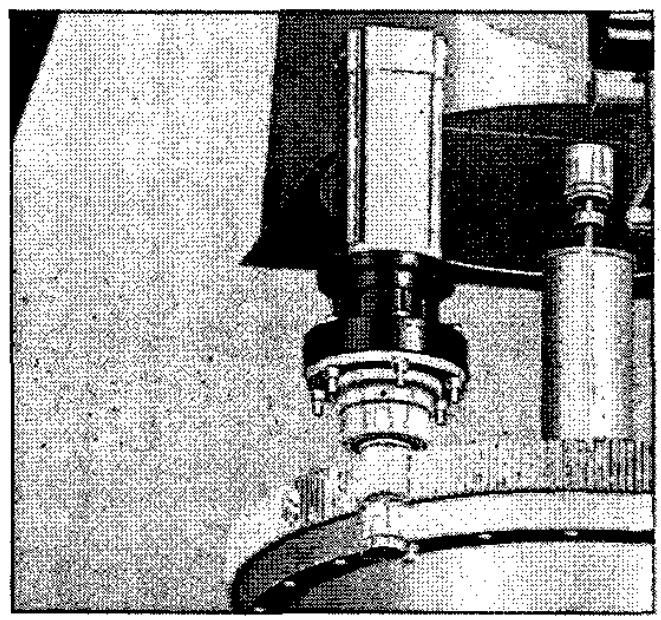

Azimuth Axis

Drive Train

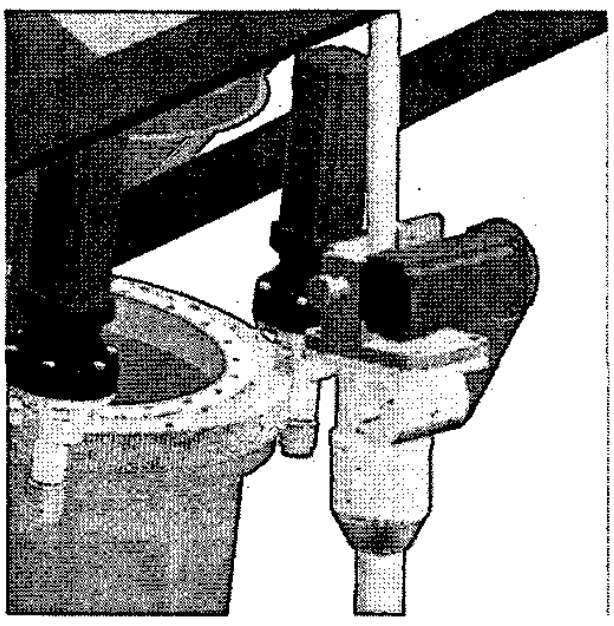

Elevation Axis Jackscrew \& Motor Pulley System

Figure 14 - Azimuth Axis Drive Train and Elevation Axis Jackscrew 
Also, composite antennas provide a lighter structure with high rigidity, which helps in reducing the gravity deformations of the antenna.

The low cost solution for the array antennas is to use one of the various infusion technologies that have been recently developed by composite structures fabricators. Some of the advantages include low cost process (room temperature curing, no need for an autoclave) and materials (prepegs), and high material utilization factors; composite infusion is a repeatable, controlled process that uses low cost tooling. The infusion transfer processes include: Vacuum Assisted Resin Transfer Molding (VARTM), Resin Transfer Molding (RTM) and Resin Film Infusion (RFI).

To add stiffness to the structure without compromising the weight, the cross-section of the structure may be increased by using lightweight foam or metallic cores sandwiched between the carbon fiber laminates.

Several approaches are being investigated to provide the reflective structure of the dish; these include embedding conductor materials onto the carbon fiber laminates, aluminum foil and meshes integrated in the material.

\section{SUMMARY}

Currently, three antennas are under construction at JPL. The 3 dishes have been received, and the truss structure and spars have been fabricated. The feed tower and pedestal are under construction. A prototype feed was fabricated and tested. The breadboard feeds are under construction. A prototype cryogenic system has been fabricated and tested, with the breadboard systems under construction.

\section{ACKNOWLEDGMENT}

The research was carried out at the Jet Propulsion Laboratory, California Institute of Technology, under a contract with the National Aeronautics and Space Administration.

\section{REFERENCES}

[1] M.S. Gatti, "The Deep Space Network Large Array," AIAA Space 2003 Conference, Long Beach, CA, September 23-25, 2003.

[2] Vahraz Jamnejad, "Shaping of 6-m Reflector," Part of Monthly Reports, DSN Array Task, January 2003.

[3] William A. Imbriale, Large Antennas of the Deep Space Network, John Wiley and Sons Inc., Hoboken, New Jersey, 2003, pp. 20-23.

[4] William A. Imbriale and Roney Abraham, "RF Optics Design of the DSN Large Array 6-meter Breadboard Antenna," JPL Interplanetary Network Progress Report, To Be Published.
[5] Daniel J. Hoppe and Harry Reilly, "Simultaneous $8-9 \mathrm{GHz} / 30-40 \mathrm{GHz}$ Feed for the DSN Large Array," JPL Interplanetary Network Progress Report, To Be Published.

[6] Michael J. Britcliffe, "Cryogenic Design of the Deep Space Network Large Array Low-Noise-Amplifier System," JPL Interplanetary Network Progress Report, To Be Published.

William A. Imbriale is a senior research scientist in the

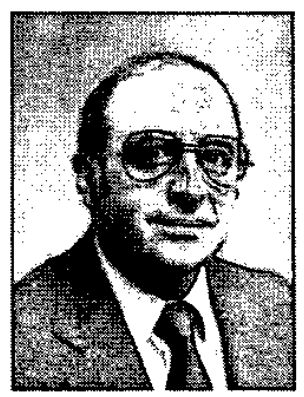
Communications Ground System Section at the Jet Propulsion Laboratory $(J P L)$, in Pasadena, California. Since starting at JPL in 1980, he has led many advanced technology developments for large ground-station antennas, lightweight spacecraft antennas, and millimeterwave spacecraft instruments. He has recently returned from a 6 month sabbatical at CSIRO in Australia where he worked with the Australian Telescope National Facility. He is currently working on the Deep Space Network Large Array, a concept to significantly increase the capability of the Deep Space Network (DSN) by arraying a large number of inexpensive small antennas. Earlier positions at JPL have included being the Assistant Manager for Microwaves in the Ground Antennas and Facilities Engineering Section and the Manager of the Radio Frequency and Microwave Subsystem Section.

Prior to joining JPL in 1980, Dr. Imbriale was employed at the TRW Defense and Space Systems Group where he was the Subproject Manager for the Antennas of the TDRSS program.

Dr. Imbriale is a Fellow of the IEEE and has an extensive list of publications.

Sander Weinreb is presently a Principal Scientist at JPL

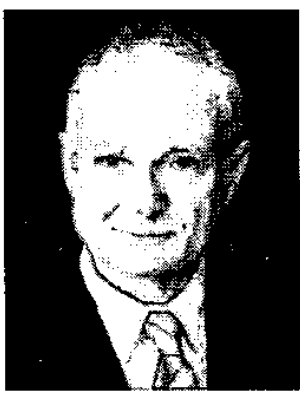
and a Faculty Associate at Caltech. Prior to this he was a Research Professor in the Department of Physics and Astronomy at $U$. of Massachusetts. His main present area of research is the development of low-noise microwave and millimeter wave integrated circuits (MMICs) for use in radio astronomy and atmospheric research. Prior to joining $U$. of Mass., during 1989-1996, he was Principal Scientist and Leader of the Millimeter-Wave Design and Test Group at Martin Marietta Laboratories where he led the design of millimeter-wave MMICs and prototype radar and radiometer systems. During 1988 and 1989 he was a visiting professor at $U$. of Virginia. Prior to this he was Head of the Electronics Division (1965-1985) and Assistant Director (1985-1988) at National Radio Astronomy 
Observatory where he was responsible for the design, construction, operation, and maintenance of radio astronomy receivers at the Green Bank, WV, and Kitt Peak, $A Z$ observatories. At $N R A O$ he led the group responsible for the design of the electronics system for the Very Large Array. Dr. Weinreb received the B.S.E.E. and Ph.D. degrees from M.I.T. in 1958 and 1963, respectively. He is the author of over 120 publications in the areas of digital correlation techniques, radio astronomy observations, array receivers, and low-noise amplifiers.

Alfonso Feria received B.S. and M.S. degrees in

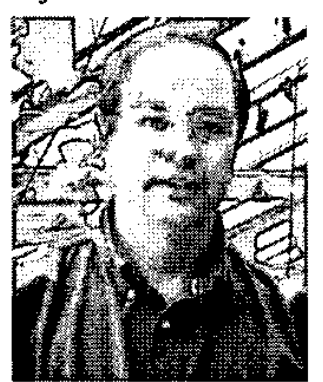
Mechanical Engineering from the National University of Mexico in 1983 and 1984, respectively. He also received a Ph.D. degree from the University of Wisconsin in 1987 with a major in Mechanical Engineering and a minor in Engineering Mechanics. He is also a registered Professional Engineer.

After working for four years at Cooper Power Systems in Milwaukee, Wisconsin, Alfonso joined the Jet Propulsion Laboratory in 1992. He was part of the team in charge of the structural design and analysis of the new $34 \mathrm{~m}$ Beam Wave Guide (BWG) antenna subnet. His duties included the Finite Element Analysis (FEA) and structural optimization of the reflector backup structure, and several mechanical and structural assignments in support of the Deep Space Network (DSN).

A few years ago, he was supporting the Advanced Radar Technology Program working on inflatable radars and composite structures for advanced radar applications. He continues to support the Gossamer Technology program working on inflatable planar arrays for radar and communication antenna applications.

Currently, Alfonso is the Technical Group Supervisor for the Antenna Mechanical and Structural Engineering Group in Section 333, Communications Ground System. His group is charge of design, fabrication, operation and maintenance of JPL's ground antennas for the DSN.

Alfonso is a member of the American Society of Mechanical Engineers (ASME) since 1986, a member of the National Society of Professional Engineers (NSPE) since 1987, a member of the American Institute of Aeronautics and Astronautics (AIAA) since 1998, and a member of the Society of Hispanic Professional Engineers (SHPE) since 1998.
Daniel J. Hoppe received the B.S. and M.S. degrees in

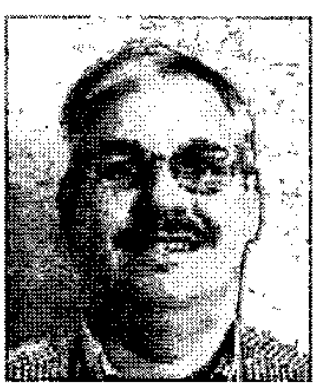
electrical engineering from the University of Wisconsin Madison in 1982 and 1983, and the Ph.D. degree, also in electrical engineering, from the University of California Los Angeles in 1994. From 1984-1996 he was a member of the technical staff at the Jet Propulsion Laboratory, Pasadena CA. From 1996-1997 he was a scientist at Hughes Space and Communications Company in El Segundo, CA. In 1998 he returned to the Jet Propulsion Laboratory where he is a principal engineer. He is currently involved in the electromagnetic analysis and design of microwave and optical devices for a number of ground-based and spacebased applications, including the DSN Large Array. Dr. Hoppe has also been a visiting lecturer at UCLA since 1995. He was awarded the NASA Exceptional Service Medal in 1993, and in 1994 he was recognized as the outstanding Ph.D. student in the School of Engineering and Applied Science at UCLA. Dr. Hoppe is a senior member of the IEEE.

Michael Britcliffe is a senior engineer at the Jet Propulsion

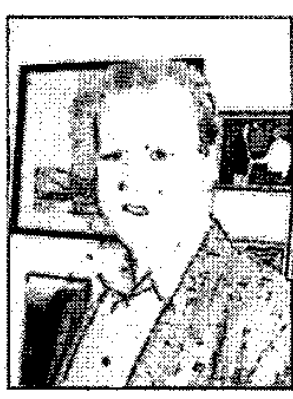
Laboratory. Currently he is a member the Antenna Microwave Engineering Group in the Communications Ground Systems Section. He received the B.S. degree in applied physics at California State University, Northridge. He has contributed to research and development programs in the NASA Deep Space Network related to cryogenically cooled low-noiseamplifier development, antenna metrology, integration and test of ground antenna systems and the development of optical communications ground receivers since 1982.

Chris Porter - Biography not available. 